\title{
Effects of Laparoscopic Hartmann Reversal on Short-term Operative Outcomes Among Vietnamese Patients
}

\section{Resultados da reversão precoce da cirurgia de Hartmann em pacientes vietnamitas}

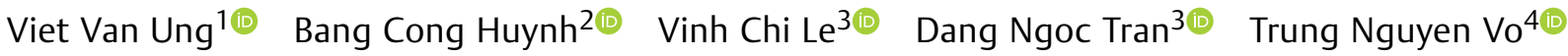 \\ Tan Van Pham ${ }^{20}$ Bac Hoang Nguyen ${ }^{20}$
}
${ }^{1}$ Department of Surgery, Faculty of Medicine, University of Medicine and Pharmacy at Ho Chi Minh City, Ho Chi Minh City, Viet Nam
2 University Medical Center, University of Medicine and Pharmacy at Ho Chi Minh City, Ho Chi Minh City, Viet Nam
${ }^{3}$ Faculty of Public Health, University of Medicine and Pharmacy at Ho Chi Minh City, Ho Chi Minh City, Viet Nam
${ }^{4}$ Faculty of Nursing, University of Medicine and Pharmacy at Ho Chi Minh City, Ho Chi Minh City, Viet Nam

\begin{abstract}
Address for correspondence Ung Van Viet, MD, PhD, Department of Surgery, Faculty of Medicine, University of Medicine and Pharmacy at Ho Chi Minh City, Ho Chi Minh City, 700000, Viet Nam (e-mail: uvviet@yahoo.com).
\end{abstract}

J Coloproctol 2021;41(2):117-123.

\begin{abstract}
Keywords

- Laparoscopic Hartmann Reversal

- effectiveness

- interval time

- Vietnamese patients

Background The reestablishment of continuity after Hartmann operation is considered a major surgical procedure with high morbidity and mortality. The optimal interval time between the Hartman procedure and reversal is controversial. Our study aimed to evaluate the effectiveness of laparoscopic Hartmann reversal and to determine the optimal timing of operation.

Methods All patients who underwent laparoscopic Hartmann reversal from 2008 to 2019 (11 years) at the University Medical Center (UMC) in Ho Chi Minh City were recruited and divided into 2 groups according to the interval time ( $\leq 4$ or $>4$ months). The short-term operative outcomes of these groups were compared.

Results There were 66 patients who underwent laparoscopic Hartmann reversal (mean age: 63.2 years old); 77\% of them had colorectal cancer, and $17 \%$ had complicated diverticular disease. The mortality rate, anastomotic leakage rate, and overall complication rate were $0 \%, 1.5 \%$, and $13.2 \%$, respectively. Early operation was performed in 36 patients, and late reversal in 28 patients. There was no difference in mortality, anastomotic leakage, operative complications, and hospital stay between the two groups.

Conclusion Laparoscopic Hartmann reversal was effective with acceptable morbidity and mortality at the UMC. There was no observed impact of the interval time between the Hartmann procedure and laparoscopic Hartmann reversal on the short-term operative outcomes.
\end{abstract}

received

June 9,2020

accepted after revision

January 15, 2020
DOI https://doi.org/

10.1055/s-0041-1730013.

ISSN 2237-9363. (c) 2021. Sociedade Brasileira de Coloproctologia. All rights reserved.

This is an open access article published by Thieme under the terms of the Creative Commons Attribution-NonDerivative-NonCommercial-License, permitting copying and reproduction so long as the original work is given appropriate credit. Contents may not be used for commercial purposes, or adapted, remixed, transformed or built upon. (https://creativecommons.org/ licenses/by-nc-nd/4.0/)

Thieme Revinter Publicações Ltda., Rua do Matoso 170, Rio de Janeiro, RJ, CEP 20270-135, Brazil 


\section{Resumo}

\section{Palavras-chave}

- reversão laparoscópica da cirurgia de Hartmann

- eficácia

- tempo de intervalo

- pacientes vietnamitas
Introdução O reestabelecimento da continuidade após a cirurgia de Hartmann é considerado um procedimento cirúrgico de grande porte com altas morbidade e mortalidade. O tempo ideal de intervalo entre a cirurgia de Hartmann e a reversão é controverso. Nosso estudo teve como objetivo avaliar a eficácia da reversão da cirurgia de Hartmann e determinar o momento ideal para a cirurgia.

Métodos Todos os pacientes submetidos à reversão laparoscópica da cirurgia de Hartmann entre 2008 e 2019 (11 anos) no Centro Médico Universitário (UMC, na sigla em inglês) na cidade de Ho Chi Minh foram recrutados e divididos em 2 grupos de acordo com o tempo de intervalo ( $\leq 4$ ou $>4$ meses). Os resultados pós-operatórios de curto prazo destes grupos foram comparados.

Resultados Um total de 66 pacientes foram submetidos à reversão laparoscópica da cirurgia de Hartmann (mediana de idade: 63.2 anos); 77 deles tinha câncer colorretal, e $17 \%$ tinham doença diverticular complicada. As taxas de mortalidade, de vazamento, e de complicações em geral foram de $0 \%, 1,5 \%$, e $13,2 \%$, respectivamente. Cirurgia precoce foi realizada em 36 pacientes, e reversão tardia foi realizada em 28 pacientes. Não houve diferença em mortalidade, vazamento anastomótico, complicações operatórias e duração da internação entre os dois grupos.

Conclusão A reversão laparoscópica da cirurgia de Hartmann foi eficaz, com morbidade e mortalidade aceitáveis no UMC. Não foi observado qualquer impacto no tempo de intervalo entre a cirurgia de Hartmann e a reversão laparoscópica nos resultados pós-operatórios de curto prazo.

\section{Introduction}

The Hartmann procedure was first introduced in 1923 by Henry Albert Hartmann, and it includes surgical resection of the rectosigmoid colon with closure of the anorectal stump and formation of an end colostomy. ${ }^{1}$ It is frequently used in the management of perforated diverticular disease of the colon or of locally invasive sigmoid cancer. ${ }^{2}$ Although there have been alternative methods used recently, such as abdominal lavage for perforated diverticular disease of the colon $^{3}$ or colonic resection with primary anastomosis, ${ }^{4}$ the Hartmann procedure is still the most commonly performed operation in the emergency situation of the abovementioned cases.

The reversal of the Hartmann procedure is a challenging operation for colorectal surgeons. The postoperative rates of complications and mortality are still quite high: mortality between 5 and $10 \%$, and complications between 13 and 50\%, including anastomotic leakage (between 0 and 15\%), incisional hernia, and wound infection. ${ }^{5}$ These complications can delay chemotherapy after operation. This results in $60 \%$ of cases of the Hartmann procedure left with a permanent stoma. ${ }^{5}$ Cases of benign diseases have a higher rate of reversal than cases of malignant diseases. ${ }^{6}$

Open surgery is still the basic method used for the reversal of the Hartmann procedure, but with relatively high rates of complications, such as wound infection, anastomotic leakage, anastomotic stenosis, sepsis, and fistula formation. ${ }^{7}$ Since the 1990s, laparoscopic surgery has been increasingly adopted as routine care for colorectal cancer, and its application in emergency colorectal surgery is becoming more widespread, with low complication rates and short hospital stay. ${ }^{8}$ However, the application of laparoscopic surgery in the reversal of the Hartmann procedure is still quite limited due to the complicated surgical techniques. Most colorectal surgeons agree that laparoscopic reversal of the Hartmann procedure is one of the most difficult laparoscopic surgeries. ${ }^{9}$ There have been very few reports since a laparoscopic reversal case was first described in $1993,{ }^{10}$ and most reports only described laparoscopic-assisted techniques. Several recent studies have shown that laparoscopic reversal of the Hartmann procedure could shorten hospital stay and reduce the rate of complications and mortality postoperatively ${ }^{2}$; however, the rate of conversion to open surgery is still high ( $\sim 25 \%)$, due to dense adhesion between the rectal stump and other tissues. ${ }^{11}$ Other authors advocate the use of hand-assisted techniques to overcome technical difficulties. ${ }^{11}$

The optimal timing of reversal remains unclear. Most surgeons advocate restoration of intestinal continuity at least between 90 and 105 days after the Hartmann procedure, and the rate of morbidity and mortality appears lower when delayed after 6 months. ${ }^{12,13}$ This period is needed for the patient to recover from the first operation, for the strings in the abdomen to loosen, and for the inflammatory phenomenon in the skin around the stoma to gradually decrease. ${ }^{14}$ In contrast, some studies support early restoration of intestinal continuity within 4 months or 4 weeks. ${ }^{15,16}$

As the laparoscopic technique has become popular in Vietnam, this minimally invasive procedure has been attempted to reverse the Hartmann procedure at the University Medical Center (UMC) in Ho Chi Minh City since 2008. To 
date, it remains unclear whether laparoscopic reversal of the Hartmann procedure is beneficial, feasible, and safe among patients, particularly in Vietnam. Therefore, the aim of the present study was to evaluate the effectiveness of laparoscopic reversal of the Hartmann procedure and to determine the optimal timing of operation in a Vietnamese population.

\section{Methods}

\section{Study Design and Setting}

The present retrospective cohort study was conducted in the Digestive Surgery Department at the UMC in Ho Chi Minh City. The UMC is one of the largest tertiary and teaching hospitals in the southern region of Vietnam. The present study was approved by the local institutional ethics committee of the UMC, under opinion number170/ĐHYD-HĐ.

\section{Data Collection}

A retrospective notes-based review was performed to assess all patients who underwent laparoscopic reversal of the Hartmann procedure between 2008 and 2019. The inclusion criteria were medical records with baseline demographics, information on the initial condition and operation, operative data relating to the reversal procedure, and postoperative events. Conversely, the exclusion criterion was refusal to participate in the study.

Two authors (Viet U. V. and Bang H. C.) performed independently the retrospective review of the medical records of the participants at the UMC. They extracted the necessary data using structured forms with predetermined measures, as stated below. In order to avoid possible bias in data collection, any mismatched information in the structured forms between the two collectors was reviewed and resolved by the corresponding author (Bac N. H.).

\section{Measures}

The outcome variables were divided into two groups: intraoperative and postoperative outcomes. The intraoperative outcomes included the operative time, need for ileostomy, open conversion, failure of reversal, and intraoperative complications; the postoperative outcomes included anastomotic leakage, time to normal bowel function, postoperative complications related to the operation itself, overall postoperative complications, length of hospital stay, and mortality.

The main explainable variable was the timing between the laparoscopic reversal of the Hartmann procedure. The patients were divided into 2 groups according to the timing of the reversal of the colostomy: early ( $\leq 4$ months) and late ( $>4$ months). We also divided the groups by several time points for robustness checks.

\section{Data Analysis}

Continuous variables were described as means \pm standard deviations (SDs) and were compared using Student $t$-tests. Categorical variables were described as numbers with percentages and were compared using the $\mathrm{X}^{2}$ test. A p-value $<0.05$ was considered statistically significant. All data analyses were performed using the $\mathrm{R}$ software, version 3.6.1 (R Foundation, Vienna, Austria).

\section{Surgical Procedure}

Please see Supplement for details (available online).

\section{Results}

\section{Preoperative Patient Characteristics}

A total of 66 patients underwent laparoscopic reversal of the Hartmann procedure. Of them, 36 were men (54.5\%), and 30 were women (45.5\%). The median age of the patients was 63.2 (range, 37-89) years old. Most of the patients (88\%) were classified under American Society of Anesthesiology score (ASA score) 2, and the remaining under ASA 3. The primary pathology was colorectal carcinoma in most patients, who accounted for $77.0 \%(n=50)$ of the study population. The median interval between the Hartmann procedure and its reversal was of 5.7 (range, 1-36) months (-Table 1).

\section{Intraoperative Outcomes}

Five patients needed conversion to open surgery due to adhesions $(n=4)$ and failure to identify the rectal stump $(n=1)$. In 2 patients, there was intestinal continuity restoration failure due to nodal metastasis $(n=1)$ and inability to dissect the rectal stump $(n=1)$. A total of 59 laparoscopic reanastomoses were successfully performed. Six patients had a defunctioning ileostomy created at the time of reversal. The median operative time was 171 (range, 90-330) minutes for all patients in the present study. Twenty patients developed intraoperative complications, including those needing enterotomies $(n=19)$ and vaginal perforation $(n=1)$, during the course of adhesiolysis. These adverse events were treated laparoscopically. These patients recovered well, with no additional postoperative morbidity (-Table 2).

\section{Postoperative Outcomes}

Postoperative complications occurred in five patients, none of whom had more than one complication. The type and frequency of the postoperative complications are listed in -Table 3. All patients recovered well, without the need for any surgical intervention. One patient had superficial wound infections, but recovered with conservative treatment with dressing application and change in antibiotics. Two patients developed anastomotic hemorrhage; one recovered with conservative treatment, and the other recovered with laparoscopic treatment. One patient developed vaginal hemorrhage that was conservatively treated. One patient had grade A clinical anastomotic leakage. The median time of discharge was 7 (range, 7-9) days postoperatively. The overall postoperative morbidity rate was $46.9 \%$, and the overall mortality rate was $0.0 \%$ (-Table 3 ).

\section{Effect of Reversal Timing}

Laparoscopic reversal of the Hartmann procedure was performed within 4 months of the initial operation in 36 
Table 1 Preoperative characteristics

\begin{tabular}{|c|c|}
\hline Patient characteristics & $n$ (total \%) \\
\hline \multicolumn{2}{|l|}{ Albumin level $(n=65)$} \\
\hline$<3.5 \mathrm{~g} / \mathrm{dL}$ & $5(7.7)$ \\
\hline$\geq 3.5 \mathrm{~g} / \mathrm{dL}$ & $60(92.3)$ \\
\hline \multicolumn{2}{|l|}{ Hemoglobin level } \\
\hline$\leq 10 \mathrm{~g} / \mathrm{dL}$ & $6(9.1)$ \\
\hline$>10 \mathrm{~g} / \mathrm{dL}$ & $60(90.9)$ \\
\hline \multicolumn{2}{|l|}{ Gender } \\
\hline Male & $36(54.5)$ \\
\hline Female & $30(45.5)$ \\
\hline Age (years old) & $63.2 \pm 11.7$ \\
\hline Body mass index $\left(\mathrm{kg} / \mathrm{m}^{2}\right)(n=24)$ & $22.0 \pm 3.2$ \\
\hline \multicolumn{2}{|l|}{$\begin{array}{l}\text { American Society of Anesthesiology } \\
\text { score (ASA score) }\end{array}$} \\
\hline 2 & $58(87.9)$ \\
\hline 3 & $8(12.1)$ \\
\hline \multicolumn{2}{|l|}{ Indication for initial surgery $(n=65)$} \\
\hline Colorectal carcinoma & $50(76.9)$ \\
\hline Sigmoid diverticulitis & $11(16.9)$ \\
\hline Others & $4(6.15)$ \\
\hline \multicolumn{2}{|l|}{ Previous abdominal surgeries } \\
\hline Once & $56(84.8)$ \\
\hline Twice & $10(15.2)$ \\
\hline \multicolumn{2}{|l|}{ Peritonitis in previous surgery $(n=25)$} \\
\hline Yes & $6(24.0)$ \\
\hline No & $19(76.0)$ \\
\hline \multicolumn{2}{|l|}{ Technique in previous surgery $(n=28)$} \\
\hline Laparoscopy & $20(71.4)$ \\
\hline Open & $8(28.6)$ \\
\hline \multicolumn{2}{|l|}{$\begin{array}{l}\text { Chemotherapy before the second } \\
\text { surgery }(n=64)\end{array}$} \\
\hline Yes & $31(48.4)$ \\
\hline No & $33(51.6)$ \\
\hline \multicolumn{2}{|l|}{ Colonoscopy $(n=60)$} \\
\hline Normal & $56(93.3)$ \\
\hline Rectal stump inflammation & $4(6.7)$ \\
\hline \multicolumn{2}{|l|}{ Barium enema $(n=57)$} \\
\hline None & $51(89.5)$ \\
\hline Stricture proximal rectum & $6(10.5)$ \\
\hline Time to reversal $(n=64)$ & $4(1-7.5)$ \\
\hline
\end{tabular}

patients and after 4 months in 28 patients. There was no significant difference between the early and late groups in terms of mortality, overall postoperative complications, postoperative complications related to the operation, and median hospital stay (-Table 4 ).
Table 2 Intraoperative characteristics

\begin{tabular}{|l|l|}
\hline Patient characteristics & $\boldsymbol{n}$ (total \%) \\
\hline Operative time (minutes) & $177.9 \pm 59.4$ \\
\hline Ileostomy & \\
\hline Yes & $6(9.1)$ \\
\hline No & $60(90.9)$ \\
\hline Open conversion $(n=65)$ & \\
\hline Yes & $5(7.7)$ \\
\hline No & $60(92.3)$ \\
\hline Failure of reversal & \\
\hline Yes & $2(3.0)$ \\
\hline No & $64(97.0)$ \\
\hline Intraoperative complications $(n=65)$ & \\
\hline No & $45(69.2)$ \\
\hline Enterotomy & $19(29.2)$ \\
\hline Vaginal perforation & $1(1.6)$ \\
\hline
\end{tabular}

Table 3 Postoperative outcomes

\begin{tabular}{|l|l|}
\hline Patient characteristics & $\boldsymbol{n}$ (total \%) \\
\hline Anastomotic leakage & \\
\hline Yes & $1(1.5)$ \\
\hline No & $65(98.5)$ \\
\hline Return to normal bowel function & $2.9 \pm 0.8$ \\
\hline $\begin{array}{l}\text { Postoperative complications related } \\
\text { to the operation }(n=63)\end{array}$ & \\
\hline None & $54(85.7)$ \\
\hline Grade I & $4(6.3)$ \\
\hline Grade II & $4(6.3)$ \\
\hline Grade IIla & $1(1.7)$ \\
\hline Grade IIIb & 0 \\
\hline Grade IV & 0 \\
\hline Overall postoperative complications & \\
\hline Yes & $34(51.5)$ \\
\hline No & $32(48.5)$ \\
\hline Length of hospital stay (days) & $7(7-9)$ \\
\hline Mortality & 0 \\
\hline
\end{tabular}

The result was quite robust because when the cutoff value was changed for the time interval, the p-value was found to be nonsignificant. The relevant data are shown in the Supplementary Material (-Supplementary Table S1 to - Table S4).

\section{Discussion}

A review of the literature revealed that only a few small case series and no randomized controlled trials on laparoscopic 
Table 4 Effect of reversal timing

\begin{tabular}{|c|c|c|c|}
\hline & \multicolumn{2}{|c|}{ Number $(\%)$ of patients $(n=64)^{*}$} & \multirow[b]{2}{*}{ p-value } \\
\hline & $\leq 4$ months & $>4$ months & \\
\hline Overall complications & $21(0.58)$ & $12(0.42)$ & $0.54(0.17-1.63)$ \\
\hline Complications related to the operation & $6(0.17)$ & $3(0.11)$ & $0.60(0.09-3.18)$ \\
\hline Renal complications & $1(0.03)$ & $0(0)$ & $\mathrm{n} / \mathrm{a}$ \\
\hline Neurological complications & $2(0.06)$ & $2(0.07)$ & $1.31(0.89-19.08)$ \\
\hline Respiratory complications & $4(0.11)$ & $3(0.11)$ & $0.96(0.13-6.25)$ \\
\hline Cardiovascular complications & $6(0.17)$ & $5(0.18)$ & $1.09(0.23-4.88)$ \\
\hline Gastrointestinal complications & $5(0.14)$ & $2(0.07)$ & $0.48(0.04-3.25)$ \\
\hline Median hospital stay & $8.1 \pm 2.9$ & $8.5 \pm 3.8$ & $0.48(-1.19-2.15)$ \\
\hline
\end{tabular}

${ }^{*} \mathrm{n}=64$. In two patients, there was intestinal continuity restoration failure. Therefore, they were not included in the analysis of the postoperative characteristics.

reversal of the Hartmann procedure have been published. Most reports of laparoscopic reversal of the Hartmann procedure were case series, with $<100$ cases, and retrospective in nature (long period). There were only three metaanalysis studies, one of which was based from the results of the American College of Surgeons National Surgical Quality Improvement Program database. ${ }^{17-19}$ Most retrospective studies included 20 patients ${ }^{20-23}$; Park et al. investigated 5 patients in particular. ${ }^{24}$ Despite the fact that our study included only 66 patients, this was still a major study on laparoscopic reversal of the Hartmann procedure conducted in Asia; furthermore, this is the only study to date that has assessed the safety and advantage of laparoscopic reversal of the Hartmann procedure within the Vietnamese setting.

The conversion rate fluctuates widely among previous studies. No conversions were conducted in the studies by Rosen et al. and Fiscon et al. ${ }^{25,26}$ In contrast, Park et al. had a rate of conversion to open surgery of $50 \%$ (19 cases). ${ }^{23}$ The high conversion rate might be attributed to the presence of associated comorbidity and the difficult technique of this procedure. The main cause of conversion was secondary to dense adhesion and to a short rectal stump. Our conversion rate was of only $7.7 \%$, which is favorably in line with that reported in most previous studies.

Intraoperative complications were difficult to avoid due to the nature of the reversal surgery. In the study by Leroy, ureteral injury managed with end-to-end ureteral anastomosis with a double J stent in one patient, major mesosigmoid hemorrhage in one patient, and acute anastomotic ischemia requiring extension of the resection and a new anastomosis in one patient were observed. ${ }^{27}$ In the study by Huynh et al., there was one case of hemorrhage from the mesentery. ${ }^{28}$ In our study, there was 1 case of vaginal perforation and 19 cases needing enterotomies, which were controlled laparoscopically. There were no postoperative complications associated with these intraoperative complications.

Laparoscopic reversal of the Hartmann procedure is often associated with lower postoperative morbidity, less severe morbidity, and lower mortality when compared with open surgery. The rate of postoperative complications varied from 8 to $18 \%$, which were mostly treated with minor and conservative management. ${ }^{2}$ Exceptionally, Leroy reported that five patients had early complications, including two anastomotic leakages (one was symptomatic and required further laparotomy), two anastomotic hemorrhages (one required reoperation for intraperitoneal hemorrhage), and one adhesional intestinal occlusion requiring reoperation, possibly due to less experience of the trainee. In the study by Zimmermann $^{31}$, major complications were significantly less observed in the laparoscopic group (laparoscopic group, $n=4$ [16.6\%] versus open group, $n=27$ [58.7\%]). In our study, the postoperative complications observed were also mostly minor in severity. One case of anastomotic hemorrhage was controlled endoscopically, while the remaining cases were controlled conservatively. There was one case of grade A anastomotic leakage, which was managed with conservative treatment. The rates of postoperative complications related to the operation and common postoperative complications were of 13.2 and $46 \%$, respectively.

Our positive result can be explained as follows: despite the originated from a procedure to treat rectosigmoid cancer, the Hartmann procedure is frequently used to treat complications of diverticulitis in Western countries. However, in Vietnam and Asia, rectosigmoid cancer is still a major indication for the Hartmann procedure. Most of our cases were rectosigmoid colon cancer in high-risk patients undergoing elective surgery (that is, 76.9\%). Adhesiolysis in these patients was less difficult to manage than complications of diverticulitis. In addition, we did not perform mobilization of the splenic flexure due to the adequate length of the sigmoid colon in most cases. We decided whether to mobilize the splenic flexure after freeing the remaining colon and evaluating the rectal stump when the intraoperative findings, notably the vascular supply and the tension-free principle, could be assessed. However, our patients were also more likely to have a low anastomosis due to prior resection of rectal tumors. In one patient, restoration of intestinal 
continuity was unsuccessful due to this reason. This challenge was overcome due to the experience and skill of the high-volume surgeons in our specialized colorectal department.

The optimal time for reversal after the Hartmann procedure remains a conflicting issue in the literature, and is based solely on the presence of diverticulitis. Unlike in most other studies conducted in Western populations, in which diverticular disease was the most common indication for the Hartmann procedure, the majority of our patients underwent this procedure for locally advanced cancer. Pearce et al. analyzed a cohort of patients who were submitted to the Hartmann procedure and reported a leakage rate of $33 \%$ among patients who underwent reversal within 6 months, and of $0 \%$ among those who underwent reversal after $>6$ months. ${ }^{13}$ Geoghegan et al. found that there was no difference between patients who underwent reversal at 1 month and a later time. ${ }^{16}$ Flemming et al. reached the same conclusion between patients who underwent surgery at 6 months and the other groups. ${ }^{29}$ Keck et al. found that there was no difference between patients who underwent reversal within 4 months and at a later time in terms of mortality, overall morbidity, or anastomotic leakage rate; however, the mean adhesion density grade was higher in the early group. ${ }^{12}$ In the study by Tan et al., there was no identifiable relationship between the timing of reversal and both intraoperative and postoperative complications. ${ }^{30}$ In our study, there was no significant difference between the patients who underwent reversal within 4 months and after 4 months in terms of intraoperative factors at the first procedure, postoperative complications, or anastomotic technique employed at the time of reversal. Therefore, delayed time was not associated with complications or anastomotic leakage. The decision on whether to perform an anastomosis or the Hartmann procedure depends on the operative experience of each surgeon and on the preference of the patient.

Our study is the first to assess the safety and advantage of laparoscopic reversal of the Hartmann procedure within a Vietnamese population. The present study replicates the findings of previous reports that laparoscopic reversal of the Hartmann procedure is a technically feasible and safe alternative for the restoration of intestinal continuity. The procedure results in minimal morbidity and short hospital stays. Our study showed the implications of performing laparoscopic reversal of the Hartmann procedure in Vietnamese patients. The present findings must be interpreted in the context of several potential limitations. One of the limitations of the present study is the absence of an open surgery cohort for comparison. Referral is a great contributing factor. Thus, a randomized controlled trial will not likely be undertaken in this area; multicenter case series (with prospectively collected data) would then be helpful in order to provide information to surgeons.

\section{Conclusion}

Laparoscopic reversal of the Hartmann procedure was effective, with acceptable morbidity and mortality at the UMC.
There was no observed impact of the interval time between the Hartmann procedure and laparoscopic reversal of the Hartmann procedure on the short-term operative outcomes.

Credit Author Statement

Bac N. H.: Conceptualization, writing- reviewing and editing. Viet U. V.: Methodology, data curation, data analysis, writing; preparation of the original draft. Tan P. V.: Data analysis, writing- reviewing and editing. Bang H. C.: Data analysis, writing- reviewing and editing. Trung V. N: Writing-reviewing and editing. Dang T. N.: Data analysis, writing-reviewing and editing. Vinh L. C.: Writing-reviewing and editing.

\section{Funding}

The present research did not receive any specific grant from funding agencies in the public, commercial, or notfor-profit sectors.

\section{Conflict of Interests}

The authors have no conflict of interests to declare.

\section{Acknowledgments}

We thank all of the patients who participated in the present study.

\section{References}

1 van Gulik TM, Mallonga ET, Taat CW. Henri Hartmann, lord of the Hôtel-Dieu. Neth J Surg 1986;38(02):45-47

2 Park J-M, Chi KC. Laparoscopic reversal of Hartmann's procedure.J Korean Surg Soc 2012;82(04):256-260

3 Swank HA, Vermeulen J, Lange JF, et al; Dutch Diverticular Disease (3D) Collaborative Study Group. The ladies trial: laparoscopic peritoneal lavage or resection for purulent peritonitis and Hartmann's procedure or resection with primary anastomosis for purulent or faecal peritonitis in perforated diverticulitis (NTR2037). BMC Surg 2010;10:29. This article is open access. https://bmcsurg.biomedcentral.com/articles/10.1186/1471-2482-10-29

4 Oberkofler CE, Rickenbacher A, Raptis DA, et al. A multicenter randomized clinical trial of primary anastomosis or Hartmann's procedure for perforated left colonic diverticulitis with purulent or fecal peritonitis. Ann Surg 2012;256(05):819-826, discussion 826-827

5 De'angelis N, Brunetti F, Memeo R, et al. Comparison between open and laparoscopic reversal of Hartmann's procedure for diverticulitis. World J Gastrointest Surg 2013;5(08):245-251

6 Roque-Castellano C, Marchena-Gomez J, Hemmersbach-Miller M, et al. Analysis of the factors related to the decision of restoring intestinal continuity after Hartmann's procedure. Int J Colorectal Dis 2007;22(09):1091-1096

7 Mazeh H, Greenstein AJ, Swedish K, et al. Laparoscopic and open reversal of Hartmann's procedure-a comparative retrospective analysis. Surg Endosc 2009;23(03):496-502

8 Reza MM, Blasco JA, Andradas E, Cantero R, Mayol J. Systematic review of laparoscopic versus open surgery for colorectal cancer. Br J Surg 2006;93(08):921-928

9 Jamali FR, Soweid AM, Dimassi H, Bailey C, Leroy J, Marescaux J. Evaluating the degree of difficulty of laparoscopic colorectal surgery. Arch Surg 2008;143(08):762-767, discussion 768

10 Gorey TF, O'Connell PR, Waldron D, Cronin K, Kerin M, Fitzpatrick JM. Laparoscopically assisted reversal of Hartmann's procedure. Br J Surg 1993;80(01):109 
11 Lucarini L, Galleano R, Lombezzi R, Ippoliti M, Ajraldi G. Laparoscopic-assisted Hartmann's reversal with the Dexterity Pneumo Sleeve. Dis Colon Rectum 2000;43(08):1164-1167

12 Keck JO, Collopy BT, Ryan PJ, Fink R, Mackay JR, Woods RJ. Reversal of Hartmann's procedure: effect of timing and technique on ease and safety. Dis Colon Rectum 1994;37(03):243-248

13 Pearce NW, Scott SD, Karran SJ. Timing and method of reversal of Hartmann's procedure. Br J Surg 1992;79(08):839-841

14 Figueiredo MN, Mège D, Maggiori L, Ferron M, Panis Y. When is the best time for temporary stoma closure in laparoscopic sphinctersaving surgery for rectal cancer? A study of 259 consecutive patients. Tech Coloproctol 2015;19(08):469-474

15 Roe AM, Prabhu S, Ali A, Brown C, Brodribb AJ. Reversal of Hartmann's procedure: timing and operative technique. Br J Surg 1991; 78(10):1167-1170

16 Geoghegan JG, Rosenberg IL. Experience with early anastomosis after the Hartmann procedure. Ann R Coll Surg Engl 1991;73(02): 80-82

17 Lucchetta A, De Manzini N. Laparoscopic reversal of Hartmann procedure: is it safe and feasible? Updates Surg 2016;68(01):105-110

18 Celentano V, Giglio MC. Case Selection for Laparoscopic Reversal of Hartmann's Procedure. J Laparoendosc Adv Surg Tech A 2018; 28(01):13-18

19 Pei KY, Davis KA, Zhang Y. Assessing trends in laparoscopic colostomy reversal and evaluating outcomes when compared to open procedures. Surg Endosc 2018;32(02):695-701

20 Gavrila D, Minciuna CE, Tudor S, Lacatus M, Vasilescu C. Laparoscopic Hartmann s Reversal: A Single Center Experience. Chirurgia (Bucur) 2019;114(02):284-289

21 Giuseppe RId FN Serafino M, et al. Laparoscopic reversal of Hartmann's procedure: A single-center experience. Asian J Endosc Surg 2019;12(04):486-491
22 Kwak HD, Kim J, Kang DW, Baek SJ, Kwak JM, Kim SH. Hartmann's reversal: a comparative study between laparoscopic and open approaches. ANZ J Surg 2018;88(05):450-454

23 Park W, Park WC, Kim KY, Lee SY. Efficacy and Safety of Laparoscopic Hartmann Colostomy Reversal. Ann Coloproctol 2018;34 (06):306-311

24 Joong-Min Park, Kyong-Choun Chi. Laparoscopic reversal of Hartmann's procedure. Korean Surg 2012;82(04):256 260

25 Rosen MJ, Cobb WS, Kercher KW, Sing RF, Heniford BT. Laparoscopic restoration of intestinal continuity after Hartmann's procedure. Am J Surg 2005;189(06):670-674

26 Fiscon V, Portale G, Mazzeo A, Migliorini G, Frigo F. Laparoscopic reversal of Hartmann's procedure. Updates Surg 2014;66(04): 277-281

$27 \mathrm{~J}$, L. Laparoscopic restoration of intestinal continuity after hartmann procedure. 2001

28 Huynh H, Trottier DC, Soto CM, et al. Laparoscopic colostomy reversal after a Hartmann procedure: a prospective series, literature review and an argument against laparotomy as the primary approach. Can J Surg 2011;54(02):133-137

29 Fleming FJ, Gillen P. Reversal of Hartmann's procedure following acute diverticulitis: is timing everything? Int J Colorectal Dis 2009;24(10):1219-1225

30 Tan WS, Lim JF, Tang CL, Eu KW. Reversal of Hartmann's procedure: experience in an Asian population. Singapore Med J 2012;53 (01):46-51

31 Markus Zimmermann, Martin Hoffmann, Tilman Laubert, KarlFrederik Meyer, Thomas Jungbluth, Uwe-Johannes Roblick, HansPeter Bruch, Erik Schlöricke. Laparoscopic Versus Open Reversal of a Hartmann Procedure: A Single-Center Study. World Journal of Surgery 2014;38:2145-2152 